\title{
Tuning Composition and Activity of Cobalt Titanium Oxide Catalysts for the Oxygen Evolution Reaction
}

\author{
L. C. Seitz ${ }^{\mathrm{a}}$, D. Nordlund ${ }^{\mathrm{b}}$, Alessandro Gallo ${ }^{\mathrm{c}}$, and T. F. Jaramillo ${ }^{\mathrm{a}, \mathrm{c}^{*}}$ \\ ${ }^{a}$ Department of Chemical Engineering, Stanford University, Stanford, California 94305, \\ USA \\ ${ }^{\mathrm{b}}$ SSRL, SLAC National Accelerator Laboratory, 2575 Sand Hill Rd, Menlo Park, \\ California 94025, USA \\ ${ }^{c}$ SUNCAT Center for Interface Science and Catalysis, SLAC National Accelerator \\ Laboratory, 2575 Sand Hill Rd, Menlo Park, California 94025, USA
}

\begin{abstract}
Understanding catalyst function to improve activity for the oxygen evolution reaction (OER) is key to increasing the overall efficiency of electrochemical water splitting, a promising method for sustainable and clean production of hydrogen. Using a straightforward and scalable sol-gel synthesis, we explore the effects of metal composition in $\mathrm{Co}_{\mathrm{x}} \mathrm{Ti}_{1-\mathrm{x}} \mathrm{O}_{\mathrm{y}}$ on electrochemical activity, atomic structure, and electronic state. Physical and electronic characterization reveal that increased amounts of $\mathrm{Ti}$ stabilize the $2+$ oxidation state of the Co precursor and lead to formation of less active CoO-like catalysts. Conversely, films with $\mathrm{Co}$ :Ti ratios of 1:1 or greater result in catalysts with high activity, correlating with greater Co 3+ character, as measured by ex situ XAS for samples as-prepared and after exposure to OER conditions. Additionally, decreasing the Ti content systematically shifts the Co redox potential from approximately 1.5 V vs. RHE with a 1:3 Co:Ti ratio to $1.0 \mathrm{~V}$ vs. RHE with no Ti, further evidence that
\end{abstract}


Ti stabilizes Co in a lower oxidation state. Controlling the oxidation state of metals in metal-oxide OER catalysts can have a profound effect on catalytic activity.

\section{Introduction}

Electrochemical water splitting is a promising method for producing hydrogen, a chemical commodity currently consumed at a rate of 50 billion kilograms per year, primarily for fertilizer. ${ }^{1}$ If this process is coupled to a renewable energy source, such as wind or solar, water splitting could provide a sustainable, clean method for production of hydrogen to replace current industrial methods and could also expand hydrogen's use as a renewable fuel. Water splitting consists of two half-reactions, the oxygen evolution reaction (OER) and the hydrogen evolution reaction (HER). The OER is the more complex of the two reactions and requires large overpotentials to proceed at relevant current densities, which severely limits the overall efficiency of water splitting. ${ }^{2,3}$ Fundamental studies to better understand material function and development of improved catalysts are needed to make further progress for this promising technology.

Among the best catalysts for this reaction are precious metal oxides, $\mathrm{RuO}_{2}$ and $\mathrm{IrO}_{2}$, but extensive research has been conducted on development of nonprecious metal oxides such as $\mathrm{MnO}_{\mathrm{x}}, \mathrm{CoO}_{\mathrm{x}}, \mathrm{CoFeO}_{\mathrm{x}}$, and $\mathrm{NiFeO}_{\mathrm{x}}$ to mitigate high cost and scarcity of precious metals. ${ }^{4-19}$ Extensive work on perovskites and double perovskites, many of which include Co, has resulted in development of very high activity catalysts, such as $\mathrm{Ba}_{0.5} \mathrm{Sr}_{0.5} \mathrm{Co}_{0.8} \mathrm{Fe}_{0.2} \mathrm{O}_{3-\delta}$ and $\operatorname{Pr}_{0.5} \mathrm{Ba}_{0.5} \mathrm{CoO}_{3-\delta}{ }^{20-23}$ Additionally, theoretical studies have investigated active phases of $\mathrm{CoO}_{\mathrm{x}}$ catalysts as well as predicted methods for further 
optimization of other OER catalysts by tuning their electronic levels through alloying or introduction of dopants. ${ }^{24-26}$

In our previous work, we identified $\mathrm{CoTiO}_{\mathrm{x}}$ as a novel, nonprecious metal catalyst for the OER which can be synthesized using a facile sol-gel technique and deposited on a variety of substrates. ${ }^{27}$ The most active catalysts were produced with low calcination temperatures and a metal composition of 50\% $\mathrm{Co}$ and $50 \% \mathrm{Ti}$ (based on the relative amounts of respective precursors in the sol-gel). Expanding upon this work, we investigate the effects of varying the metal composition on the local geometric structure, activity, and electronic structure of this material system.

This study involves the use of both hard X-rays and soft X-rays in spectroscopic studies of local structure and chemical state of these catalysts. Extended X-ray absorption fine structure (EXAFS) is employed to determine effects of material composition on the local structure of materials, even in the absence of long range order, which is important as the highest activity catalysts exhibit low crystallinity since high-temperature calcination steps were avoided. ${ }^{27,}{ }^{28}$ Hard X-rays are used to probe number and location of atoms surrounding a central X-ray absorbing atom via interference patterns. Interactions between the backscattered electrons of neighboring atoms and waves of the emitted photoelectrons from the central atom result in oscillations above the absorption edge. The Fourier transform of these oscillations reveals a pattern of distinct peaks which can be used to identify structural motifs consistent with known crystalline materials. Structural data from EXAFS are also correlated with results from soft X-ray absorption spectroscopy (XAS) which probe the material surface electronic structure, which is particularly relevant for these electrochemical catalysts. Ex situ soft XAS is a powerful 
tool which can be used to determine oxidation state and element-specific electronic structure information. The use of soft X-rays allows one to probe the valence structure of first row transition metals including fine spectral features caused by multiplet effects. The use of both hard and soft X-rays in this study provides a distinctive insight into the local structural details and the surface oxidation state of the catalyst which could not be understood with only bulk sensitive or non-synchrotron techniques.

\section{Experimental Methods}

\subsection{Sample Preparation}

A sol-gel was prepared using a published procedure; briefly, cobalt acetate (Sigma Aldrich, 99.999\% trace metals basis) and titanium (IV) isopropoxide (Sigma Aldrich, 99.999\% trace metals basis) were dissolved separately in 2-methoxyethanol (Acros Organics, extra pure, $>99 \%) .{ }^{28}$ Varying ratios of the two precursor solutions were mixed and diluted 4 fold to produce films ranging in metal composition from 100\% Co and 0\% $\mathrm{Ti}$ to $0 \% \mathrm{Co}$ and $100 \%$ Ti. Fluorine-doped tin oxide (FTO) substrates on aluminoborosilicate or fused silica (Solaronix, sheet resistance of $10 \Omega / \mathrm{sq}$ ) were ultrasonically cleaned using acetone and isopropanol and then dipcoated in the sol gel solutions. All samples were heated in air in a fused silica tube furnace (Mellen Company) for two hours at $150^{\circ} \mathrm{C}$.

\subsection{Assessment of Material Surface Composition}

X-ray photoemission spectroscopy (XPS) was used to determine the relative amounts of $\mathrm{Co}$ and $\mathrm{Ti}$ at the film surface for each sample. XPS was performed using a Phi VersaProbe spectrometer with an $\mathrm{Al} \mathrm{K} \alpha$ source. Film surface compositions were 
determined using MultiPak (Physical Electronics, Inc.) fitting software to determine an appropriate baseline and multiply relative areas by sensitivity factors for Co and Ti.

\subsection{Identification of Local Structure}

A separate set of samples was prepared on bare fused silica substrates (Chemglass Life Sciences) to avoid signal from FTO. Ex situ extended X-ray absorption fine structure (EXAFS) was used to measure structural information for these materials since all films were found to lack long range order in X-ray diffractograms. Cobalt $\mathrm{K}$ edge $(7709 \mathrm{eV})$ measurements were performed at the 20-pole, 2.0-Tesla Wiggler beamline 4-1 at the Stanford Synchrotron Radiation Lightsource (SSRL) with a Lytle fluorescence detector. Four separate scans for each sample were analyzed using the Demeter software package and a linear pre-edge function was subtracted and the data were normalized by edge height using Athena software. ${ }^{29}$ A smooth, third order polynomial approximating the absorption background of an isolated atom was subtracted to yield $\chi(\mathrm{k})$. The data were then $\mathrm{K}^{3}$-weighted and Fourier transformed to reveal reduced distances to cobalt nearest neighbors. The coordination number $(\mathrm{N})$, the distance of the scattering atoms $(\mathrm{R})$, and the mean-squared displacement $\left(\sigma^{2}\right)$ of the neighboring scatterers were obtained by nonlinear fitting with least-squares refinement of the first shell $(1.0-2.2 \AA)$ in R-space using the EXAFS equation as implemented in the Artemis software. ${ }^{30}$ The Co $\mathrm{K}$ amplitude reduction factor $\left(\mathrm{S}_{0}{ }^{2}\right)$ was set to 0.9 and the shift in threshold energy $\left(\Delta \mathrm{E}_{0}\right)$ was allowed to vary.

\subsection{Electrochemical Testing}

The catalytic activity was assessed using cyclic voltammetry (CV, BioLogic, VSP) in a 3 electrode electrochemical compression cell made of polytetrafluoroethylene with an 
exposed working electrode area of $0.5 \mathrm{~cm}^{2}$. Fresh samples were swept from $0.95-1.90 \mathrm{~V}$ vs. RHE at a scan rate of $25 \mathrm{mV} / \mathrm{s}$ in $0.1 \mathrm{M} \mathrm{KOH}$ (Sigma-Aldrich, $99.99 \%$ trace metals basis). A coiled platinum wire counter electrode and $\mathrm{Ag} / \mathrm{AgCl} 4 \mathrm{M} \mathrm{KCl}$ (Fisher Scientific, Accumet) reference electrode were used. All data were post corrected for $100 \%$ of the solution series resistance measured by impedance spectroscopy and shifted to a reversible hydrogen electrode (RHE) scale.

\subsection{Identification of Surface Oxidation State}

Ex situ soft X-ray absorption spectroscopy (XAS) on the cobalt L edge was used to probe the surface oxidation states of the catalyst as prepared and after exposure to OER conditions. To investigate samples under approximated OER conditions, identical samples were electrochemically swept to two different potentials ( 1.65 or $1.90 \mathrm{~V}$ vs. RHE), held for 10 minutes, and removed from the electrolyte under potential control such that the surface remained in its oxidized state. XAS measurements were performed on the 31-pole wiggler beamline 10-1 at SSRL using a ring current of $500 \mathrm{~mA}$ and a 1000 lines* $\mathrm{mm}^{-1}$ spherical grating monochromator with $40 \mu \mathrm{m}$ entrance and exit slits, providing $\sim 10^{11}$ photons* $\mathrm{s}^{-1}$ at $0.3 \mathrm{eV}$ resolution in a $1 \mathrm{~mm}^{2}$ beam spot. All data were acquired in a single load at room temperature and under ultrahigh vacuum $\left(10^{-9}\right.$ Torr). Total electron yield (TEY) was measured via the sample drain current and all spectra were normalized by the incoming flux, measured from a thin grid with freshly evaporated gold positioned upstream of the sample chamber. A cobalt oxide reference sample, intercepting a few percent of the beam upstream and recorded simultaneously, was used to calibrate the energy of all scans with a relative energy precision of $+/-25 \mathrm{meV}$. Reference powders were purchased (lithium cobalt(III) oxide, Sigma Aldrich, 99.8\% 
trace metals basis, cobalt(II,III) oxide, Sigma Aldrich, 99.995\% metals basis, cobalt(II) oxide, Sigma Aldrich, >99.99\% metals basis, cobalt(II) oxide, Alfa Aesar, $99.998 \%$ metals basis, cobalt titanium oxide, Santa Cruz Biotechnology, 99.8\% metals basis) and affixed to the aluminum sample holder using conductive carbon tape for comparison. Data was processed such that the baseline was subtracted, the area was normalized within the range of 770 to $796 \mathrm{eV}$, and all scans were shifted to match the $\mathrm{L}_{\mathrm{III}}$ peak $(775.3 \mathrm{eV})$ of $\mathrm{LiCoO}_{2}$ reference powder to that in de Groot et al. ${ }^{31}$

\section{Results and Discussion}

\subsection{Material Composition \& Structure}

XPS was used to determine the surface composition of catalyst films compared to the expected bulk composition from the relative amounts of Co and Ti precursors used in the sol-gel. Figure 1 shows these results for each of the catalysts, plotted with a gray line indicating where the measured surface Co composition would be equal to the expected bulk Co composition. We observe that films with greater than $50 \%$ cobalt (on a metalbasis) in the sol-gel consistently exhibit lower than expected content of surface Co. This could potentially be due to difficulties in dissolving the cobalt acetate precursor leading to decreased Co in the sol-gel, which suggests that this decreased Co content is potentially also representative of the actual bulk composition. Otherwise, the surface Co compositions match the expected bulk Co compositions quite well. Measured surface Co compositions will be used to refer to samples for the remainder of the manuscript as they are most relevant to the catalysis.

FIGURE 1 HERE 
While investigating the crystal structure of films prepared for this work, it was observed that none of them exhibited peaks in X-ray diffractograms. However, significant shifts in short range order were identified using EXAFS the cobalt K edge. Figure 2 shows the Fourier transform (FT) of EXAFS for four catalysts which span the range of $50 \%$ to $100 \%$ cobalt metal content. Qualitatively, we observe that the $100 \%$ and $86 \%$ Co samples $\left(\mathrm{CoO}_{\mathrm{y}}\right.$ and $\left.\mathrm{Co}_{0.86} \mathrm{Ti}_{0.14} \mathrm{O}_{\mathrm{y}}\right)$ are very similar to one another and likewise, the $70 \%$ and $50 \%$ Co samples $\left(\mathrm{Co}_{0.7} \mathrm{Ti}_{0.3} \mathrm{O}_{\mathrm{y}}\right.$ and $\left.\mathrm{Co}_{0.5} \mathrm{Ti}_{0.5} \mathrm{O}_{\mathrm{y}}\right)$ are very similar. The two samples with higher Co content have more narrow peaks and indicate longer range order than the samples with lower Co content. Peak broadening can occur due to interference from small differences in atomic spacing from the presence of more than one material phase while peak amplitude is generally affected by the number of bonds as well as the distance between the central atom and surrounding atoms. As an example, the first large peak in all of these samples (at $\sim 1.5 \AA$ reduced distance) is the Co-O peak, which provides information about the oxygen coordination as well as the bond distance. Reduced distances of the peaks from the FT shown in Figure 2 are $0.3-0.4 \AA$ shorter than actual bond lengths, which are listed in Table 1 for the first shell fit, using a single path for the Co-O bond distance for three of the samples. ${ }^{32,33}$

\section{FIGURE 2 HERE}

The Co precursor used in this synthesis, cobalt acetate tetrahydrate, has been shown to dehydrate and even slightly decompose when heated to $150^{\circ} \mathrm{C}$ in inert atmospheres (nitrogen or argon). ${ }^{34}$ EXAFS peak fitting indicates some dehydration and decomposition of the precursor after calcination in air at $150^{\circ} \mathrm{C}$ as well, since none of the samples have coordination numbers $(\mathrm{CN})$ or $\mathrm{Co}-\mathrm{O}$ bond distances consistent with the cobalt acetate 
tetrahydrate $(2.09 \AA, \mathrm{CN}=6) .{ }^{35} \mathrm{We}$ also note that increased $\mathrm{Ti}$ content $(30 \%$ or $50 \% \mathrm{Ti})$ favors a longer Co-O distance of $2.01 \AA$ or $2.03 \AA$ as well as an increased Co coordination number (5.6 to 5.1) compared to the samples with less $\mathrm{Ti}(0 \%$ or $14 \%)$ which have a fitted Co-O distance of $1.92 \AA$ or $1.91 \AA$ and significantly lower coordination number (3.6 or 3.9). The $\mathrm{Ti}$ precursor, titanium isopropoxide, likely interacts with the cobalt acetate such that dehydration becomes more difficult or perhaps even condensation towards an amorphous $\mathrm{CoO}$ structure is assisted. If present in films with increased $\mathrm{Ti}$ content, the domains of $\mathrm{CoO}$ are expected to be quite small since the coordination number is significantly lower for these films compared to crystalline $\mathrm{CoO}$ $(\mathrm{CN}=6)$. Films with little or no $\mathrm{Ti}$, have $\mathrm{Co}-\mathrm{O}$ distances that are close to the average value for $\mathrm{Co}_{3} \mathrm{O}_{4}(1.95 \AA)$, but again the coordination numbers are significantly lower than expected for bulk $\mathrm{Co}_{3} \mathrm{O}_{4}$ (4.67) so we might expect to have only small domains forming. ${ }^{36-38}$ The second large peak in Figure 2, with a reduced distance close to $2.5 \AA$, is only present for the films with $100 \%$ and $86 \%$ Co. Reduced distances in this range are characteristic of layered oxides and have been observed in other cobalt oxide electrocatalysts indicating the presence of di- $\mu$-oxo bridges. ${ }^{39,40}$ Absence of this peak for films with greater Ti content indicates minimal structural order.

\begin{tabular}{cccc}
\hline Metal Composition & $\begin{array}{c}\text { Coordination } \\
\text { Number }\end{array}$ & $\begin{array}{c}\text { Co-O Bond } \\
\text { Distance }(\mathbf{\AA})\end{array}$ & $\begin{array}{c}\text { Debye-Waller } \\
\text { Factor }\left(\AA^{\mathbf{2}}\right)\end{array}$ \\
\hline $\mathbf{1 0 0 \%} \mathbf{C o}$ & $3.6(0.6)$ & $1.92(0.01)$ & $0.006(0.001)$ \\
$\mathbf{8 6 \%} \mathbf{C o}, \mathbf{1 4 \%} \mathbf{~ T i}$ & $3.9(0.8)$ & $1.91(0.01)$ & $0.007(0.002)$ \\
$\mathbf{7 0 \%} \mathbf{C o}, \mathbf{3 0 \%} \mathbf{~ T i}$ & $5.6(0.7)$ & $2.01(0.01)$ & $0.013(0.001)$ \\
\hline
\end{tabular}




$\begin{array}{llll}\mathbf{5 0 \%} \mathbf{C o}, \mathbf{5 0 \%} \mathrm{Ti} & 5.1(0.8) & 2.03(0.05) & 0.0120(0.0007)\end{array}$

Table 1: Coordination number, $\mathrm{Co}-\mathrm{O}$ bond distances, and Debye-Waller Factors (presented with error) resulting from first shell EXAFS analysis.

\subsection{Electrochemical Activity}

Catalytic activity was assessed for several sets of samples with a range of $\mathrm{Co}$ and $\mathrm{Ti}$ compositions in basic electrolyte. Figure 3a shows the forward sweep of the first $\mathrm{CV}$ for a set of samples ranging from $100 \%$ to $0 \%$ Co metal content. We observe very similar activity for samples with greater than $50 \%$ Co, while the activity quickly decreases for samples with lower Co content. A clear overall activity trend is shown in Figure $3 \mathrm{~b}$ which plots the overpotential required to reach $10 \mathrm{~mA} / \mathrm{cm}^{2}$ (as measured by $\mathrm{CV}$ ) for 35 samples with various stoichiometries. We again observe that the activity is fairly constant for films with greater than 50\% Co content, and the activity decreases exponentially for films with lower Co content.

If we focus on the potential range before OER onsets, as is shown in Figure $3 c$, we see large oxidation peaks for films with greater than $25 \%$ Co metal composition. Although the presence of a peak indicating Co oxidation from a $2+$ to a $3+$ state is expected in this region, the large shift observed in this peak is quite remarkable. As is shown in Figure 3d, for all samples with an identifiable oxidation peak, the location of these peaks shifts linearly with Co composition over a range of $0.4 \mathrm{~V}$. This suggests that tuning the $\mathrm{Co}_{\mathrm{x}} \mathrm{Ti}_{1-}$ ${ }_{x} \mathrm{O}_{\mathrm{y}}$ composition in turn modifies the electrochemical oxidation of Co. Similarly to the EXAFS results, this suggests a bonding interaction between the Co and the Ti which either stabilizes the $2+$ state of the cobalt acetate precursor or causes formation of small stabilized $\mathrm{CoO}$ domains. As the most active phase of Co has previously been identified to be $\mathrm{CoOOH}$ in a $3+$ oxidation state, ${ }^{26}$ our results suggest that high contents of $\mathrm{Ti}$ (above 
$60 \%$ ) result in less active catalysts due to an increase in $\mathrm{Co}^{2+}$ at the expense of $\mathrm{Co}^{3+}$. In other, related work, very small shifts (less than $0.05 \mathrm{~V}$ ) in the oxidation peak of Ni have been observed previously on $\mathrm{Ni}_{1-\mathrm{x}} \mathrm{Fe}_{\mathrm{x}} \mathrm{OOH}$ catalysts with varying amounts of $\mathrm{Fe} .{ }^{17}$ Shifts in the Co oxidation peak location have also been reported for $\mathrm{Co}_{1-\mathrm{x}} \mathrm{Fe}_{\mathrm{x}} \mathrm{OOH}{ }^{41}$ However, in this case the Fe was identified as the active OER material while Co provided a conductive network since $\mathrm{FeOOH}$ has poor conductivity at OER potentials.

\section{FIGURE 3 HERE}

\subsection{Surface Electronic Structure}

Ex situ soft X-ray absorption spectroscopy (XAS) was measured at the Cobalt L edge to investigate the electronic structure of the $\mathrm{Co}_{\mathrm{x}} \mathrm{Ti}_{1-\mathrm{x}} \mathrm{O}_{\mathrm{y}}$ films as a function of metal composition and to determine the effect of exposure to OER conditions. L edge XAS of first row transition metal oxides is a sensitive probe of oxidation and symmetry through the direct dipole transition into the unoccupied frontier orbitals. ${ }^{31,42}$ Figure 4 shows TEY scans, which probe the catalyst surface $(2-4 \mathrm{~nm})$, at the Co L-edge XAS spectra in an extended region covering both the $\mathrm{L}_{\mathrm{III}}\left(\mathrm{Co} 2 \mathrm{p}_{3 / 2}\right)$ and the $\mathrm{L}_{\mathrm{II}}$ region $\left(\text { Co } 2 \mathrm{p}_{1 / 2}\right)^{43,44}$ Standard powder references are shown in Figure $4 \mathrm{a}$ and identical sets of $\mathrm{Co}_{\mathrm{x}} \mathrm{Ti}_{1-\mathrm{x}} \mathrm{O}_{\mathrm{y}}$ samples are shown as-prepared (Figure 4b), held at $1.65 \mathrm{~V}$ vs. RHE (Figure 4c), and held at $1.9 \mathrm{~V}$ vs. RHE (Figure 4d). The reference samples display a large sensitivity to oxidation state and local bonding environment with a rich multiplet structure, consistent with earlier studies, with the exception that the $\mathrm{CoO}$ reference powder is slightly oxidized. $^{31,42}$

FIGURE 4 HERE 
The as-prepared $\mathrm{Co}_{\mathrm{x}} \mathrm{Ti}_{1-\mathrm{x}} \mathrm{O}_{\mathrm{y}}$ samples exhibit features which are mostly consistent with the $2+$ valence structure observed in the $\mathrm{CoTiO}_{3}$ or cobalt acetate $\left(\mathrm{CoO}_{4} \mathrm{C}_{4} \mathrm{H}_{6} \cdot 4 \mathrm{H}_{2} \mathrm{O}\right)$ reference powders. However, for the samples with Co content greater than $60 \%$, there is a slight shift to higher energy and presence of a small peak at $775 \mathrm{eV}$, indicating some 3+ character in these films. This trivalent feature is most prominent for the $100 \%$ and $86 \%$ Co films and is only visible as a shoulder for $67 \%$ and $66 \%$ Co films. This data is consistent with all previous results indicating that addition of $\mathrm{Ti}$ is stabilizing the $2+$ state of the Co precursor. After exposure to OER at both $1.65 \mathrm{~V}$ and $1.90 \mathrm{~V}$ vs. RHE, we see that samples with higher Co content display significant increase in intensity of the main peak for trivalent cobalt both in $\mathrm{L}_{\mathrm{III}}\left(\right.$ near $775 \mathrm{eV}$ ) as well as $\mathrm{L}_{\mathrm{II}}($ near $789 \mathrm{eV})$. Even samples with Co content as low as $25 \%$, which exhibited primarily $2+$ oxidation as prepared, clearly indicate presence of Co $3+$. We observe very slight differences in the intensity of this feature for trivalent Co, with decreasing Co content having slightly lower $3+$ character, but overall we detect nearly equal amounts of $3+$ character for films ranging from $100 \%$ to $26 \%$ Co. This suggests that although increased Ti content stabilized the $2+$ oxidation state of the Co precursor in the as-prepared films and shifted the oxidation peak to higher potentials, the Co is still able to oxidize electrochemically to the more active $3+$ state even at low concentrations.

\section{Conclusions}

We have explored the effect of metal composition on the catalytic activity and structure of a nonprecious $\mathrm{Co}_{\mathrm{x}} \mathrm{Ti}_{1-\mathrm{x}} \mathrm{O}_{\mathrm{y}}$ mixed metal oxide catalyst for the OER. Although all of the catalysts were found to lack long range order, significant changes in local structure were identified with EXAFS. Films with the highest Co content exhibited shorter Co-O bond 
distances $(1.92 \AA)$ and had an average coordination of 3 compared to films with $70 \%$ or $50 \%$ cobalt $\left(\mathrm{Co}_{0.7} \mathrm{Ti}_{0.3} \mathrm{O}_{\mathrm{y}}\right.$ or $\left.\mathrm{Co}_{0.5} \mathrm{Ti}_{0.5} \mathrm{O}_{\mathrm{y}}\right)$ which had $\mathrm{Co}-\mathrm{O}$ bond distances of 2.01 and $2.03 \AA$, respectively, and were 5 fold coordinated. These results suggest that the cobalt acetate precursor may be partially dehydrated and potentially decomposed even at low temperature calcination, as the measured $\mathrm{Co}-\mathrm{O}$ bond distance and coordination numbers of the prepared catalyst do not match that of cobalt acetate. However, we also see that addition of Ti stabilizes the $2+$ state of the precursor, perhaps through the formation of small CoO domains. Ex situ XAS supports these results and shows that films with lowest Ti content have the highest $3+$ character as prepared. Electrochemical testing confirmed that increased Ti content stabilized the 2+ phase of $\mathrm{Co}$ as the Co oxidation peak location was shifted to more oxidizing potentials with higher Ti content. This was also correlated with a decrease in activity for films with greater than $50 \% \mathrm{Ti}\left(\mathrm{Co}_{0.5} \mathrm{Ti}_{0.5} \mathrm{O}_{\mathrm{y}}\right)$. Despite shifted oxidation potentials for the Co, films with up to $74 \%$ Ti content still exhibit significant Co 3+ character after exposure to OER conditions.

\section{Acknowledgements}

This work was supported as part of the Center on Nanostructuring for Efficient Energy Conversion (CNEEC) at Stanford University, an Energy Frontier Research Center funded by the U.S. Department of Energy, Office of Science. This work was partially supported by the US Department of Energy, Basic Energy Science through the SUNCAT Center for Interface Science and Catalysis. LCS received fellowship support from the National Science Foundation Graduate Research Fellowship. AG acknowledges the Department of Energy, Laboratory Directed Research and Development funding, under Contract No. DE-AC02-76SF00515. Use of the Stanford Synchrotron Radiation Lightsource (SSRL), 
SLAC National Accelerator Laboratory, is supported by the U.S. Department of Energy, Office of Science, Office of Basic Energy Sciences under Contract No. DE-AC0276SF00515. The authors acknowledge technical assistance from Dr. Ryan Davis at SSRL. Part of this work was performed at the Stanford Nano Shared Facilities (SNSF). 


\section{References}

1. $\quad$ N. Armaroli and V. Balzani, ChemSusChem, 2011, 4, 21-36.

2. I. C. Man, H. Y. Su, F. Calle-Vallejo, H. A. Hansen, J. I. Martinez, N. G. Inoglu, J. Kitchin, T. F. Jaramillo, J. K. Norskov and J. Rossmeisl, Chemcatchem, 2011, 3, 1159-1165.

3. L. Trotochaud and S. W. Boettcher, Scripta Materialia, 2014, 74, 25-32.

4. S. Trasatti, Electrochimica Acta, 1984, 29, 1503-1512.

5. T. Reier, Teschner, D., Lunkenbein, T., Bergmann, A., Selve, S., Kraehnert, R., Schlögl, R. Strasser, P., Journal of the Electrochemical Society, 161, F876-F882.

6. Y. Lee, J. Suntivich, K. J. May, E. E. Perry and Y. Shao-Horn, Journal of Physical Chemistry Letters, 2012, 3, 399-404.

7. K. A. Stoerzinger, L. Qiao, M. D. Biegalski and Y. Shao-Horn, Journal of Physical Chemistry Letters, 2014, 5, 1636-1641.

8. Y. Gorlin and T. F. Jaramillo, Journal of the American Chemical Society, 2010, 132, 13612-13614.

9. R. Brimblecombe, A. Koo, G. C. Dismukes, G. F. Swiegers and L. Spiccia, Journal of the American Chemical Society, 2010, 132, 2892-2894.

10. M. Morita, C. Iwakura and H. Tamura, Electrochimica Acta, 1979, 24, 357-362.

11. B. S. Yeo and A. T. Bell, Journal of the American Chemical Society, 2011, 133, 5587-5593.

12. A. J. Esswein, Y. Surendranath, S. Y. Reece and D. G. Nocera, Energy \& Environmental Science, 2011, 4, 499-504.

13. M. W. Kanan and D. G. Nocera, Science, 2008, 321, 1072-1075.

14. Y. Liang, Y. Li, H. Wang, J. Zhou, JianWang, T. Regier and H. Dai, Nature Materials, 2011, 10, 780-786.

15. W. Bian, Z. Yang, P. Strasser and R. Yang, Journal of Power Sources, 2014, 250, 196-203.

16. L. Trotochaud, J. K. Ranney, K. N. Williams and S. W. Boettcher, Journal of the American Chemical Society, 2012, 134, 17253-17261.

17. L. Trotochaud, S. L. Young, J. K. Ranney and S. W. Boettcher, Journal of the American Chemical Society, 2014, 136, 6744-6753.

18. C. C. L. McCrory, S. Jung, J. C. Peters and T. F. Jaramillo, Journal of the American Chemical Society, 2013, 135, 16977-16987.

19. P. C. K. Vesborg and T. F. Jaramillo, RSC Advances, 2012, 2, 7933-7947.

20. J. Suntivich, K. J. May, H. A. Gasteiger, J. B. Goodenough and Y. Shao-Horn, Science, 2011, 334, 1383-1385.

21. A. Grimaud, K. J. May, C. E. Carlton, Y.-L. Lee, M. Risch, W. T. Hong, J. Zhou and Y. Shao-Horn, Nat Commun, 2013, 4.

22. A. Grimaud, C. E. Carlton, M. Risch, W. T. Hong, K. J. May and Y. Shao-Horn, Journal of Physical Chemistry C, 2013, 117, 25926-25932.

23. M. Risch, A. Grimaud, K. J. May, K. A. Stoerzinger, T. J. Chen, A. N. Mansour and Y. Shao-Horn, The Journal of Physical Chemistry C, 2013, 117, 8628-8635.

24. M. García-Mota, A. Vojvodic, H. Metiu, I. C. Man, H.-Y. Su, J. Rossmeisl and J. K. Nørskov, Chemcatchem, 2011, 3, 1607-1611.

25. M. García-Mota, A. Vojvodic, F. Abild-Pedersen and J. K. Nørskov, The Journal of Physical Chemistry C, 2012, 117, 460-465. 
26. M. Bajdich, M. García-Mota, A. Vojvodic, J. K. Nørskov and A. T. Bell, Journal of the American Chemical Society, 2013, 135, 13521-13530.

27. L. C. Seitz, B. A. Pinaud, D. Nordlund, Y. Gorlin, A. Gallo and T. F. Jaramillo, J Electrochem Soc, 2015, 162, H841-H846.

28. S. H. Chuang, R. H. Gao, D. Y. Wang, H. P. Liu, L. M. Chen and M. Y. Chiang, Journal of the Chinese Chemical Society, 2010, 57, 932-937.

29. B. Ravel, Newville, M., Journal of Synchrotron Radiation, 2005, 12, 537-541.

30. D. E. Sayers, E. A. Stern and F. W. Lytle, Physical Review Letters, 1971, 27, 1204-1207.

31. F. M. F. de Groot, M. Abbate, J. vanElp, G. A. Sawatzky, Y. J. Ma, C. T. Chen and F. Sette, J. Phys.: Condens. Matter 5, 1993, 2277-2288.

32. B. K. Teo, Springer Berlin Heidelberg, 1986.

33. J. E. Penner-Hahn, Coordination Chemistry Reviews, 1999, 190-192, 1101-1123.

34. R. W. Grimes and A. N. Fitch, Journal of Materials Chemistry, 1991, 1, 461-468.

35. A. N. Sobolev, E. B. Miminoshvili, K. E. Miminoshvili and T. N. Sakvarelidze, Acta Crystallographica, 2003, 59, m836-m837.

36. W. L. Smith and A. D. Hobson, Acta Crystallographica Section B, 1973, 29, 362363.

37. K. Tohji, Y. Udagawa, S. Tanabe, T. Ida and A. Ueno, Journal of the American Chemical Society, 1984, 106, 5172-5178.

38. M. Shirai, K. Asakura and Y. Iwasawa, Catal Lett, 1992, 15, 247-254.

39. M. Risch, V. Khare, I. Zaharieva, L. Gerencser, P. Chernev and H. Dau, Journal of the American Chemical Society, 2009, 131, 6936-6937.

40. T. Ama, M. M. Rashid, T. Yonemura, H. Kawaguchi and T. Yasui, Coordination Chemistry Reviews, 2000, 198, 101-116.

41. M. S. Burke, M. G. Kast, L. Trotochaud, A. M. Smith and S. W. Boettcher, Journal of the American Chemical Society, 2015, 137, 3638-3648.

42. F. M. F. de Groot, J. C. Fuggle, B. T. Thole and G. A. Sawatzky, Physical Review $B, 1990,42,5459-5468$.

43. B. H. Frazer, B. Gilbert, B. R. Sonderegger and G. De Stasio, Surface Science, 2003, 537, 161-167.

44. M. Abbate, J. B. Goedkoop, F. M. F. de Groot, M. Grioni, J. C. Fuggle, S. Hofmann, H. Petersen and M. Sacchi, Surface and Interface Analysis, 1992, 18, 65-69.

\section{FIGURE CAPTIONS}

Figure 1: Surface composition of $\mathrm{Co}_{\mathrm{x}} \mathrm{Ti}_{1-\mathrm{x}} \mathrm{O}_{\mathrm{y}}$ films as determined by XPS compared to the expected bulk metal composition based on values of $\mathrm{x}$ ranging from 0 to 1 . The gray line indicates where the measured Co surface composition equals the expected Co bulk composition.

Figure 2: FT of EXAFS spectra for $\mathrm{Co}_{\mathrm{x}} \mathrm{Ti}_{1-\mathrm{x}} \mathrm{O}_{\mathrm{y}}$ films prepared on fused silica with different metal compositions showing reduced distances for atoms surrounding Co. FT of $\mathrm{k}^{3}$ weighted data were taken over a k-range beginning at the first node between 2 and 3 
and ending at 10 or 11 , when the data becomes too noisy. Both modulus and imaginary parts are shown with spectra offset to improve clarity.

Figure 3: (a) Electrochemical activity in basic electrolyte for a set of $\mathrm{Co}_{\mathrm{x}} \mathrm{Ti}_{1-\mathrm{x}} \mathrm{O}_{\mathrm{y}}$ samples with $\mathrm{x}$ values ranging from 0 to 1 . (b) Overall trend in electrochemical activity for multiple sets of samples. (c) The Co oxidation peak location shifts from approximately $1.0 \mathrm{~V}$ vs RHE to $1.5 \mathrm{~V}$ vs. RHE with increased Ti content. (d) The trend in oxidation peak location vs. metal composition is linear for several sets of samples.

Figure 4: (a) Co L edge XAS for reference powders at various oxidation states. Three identical sets of $\mathrm{Co}_{\mathrm{x}} \mathrm{Ti}_{1-\mathrm{x}} \mathrm{O}_{\mathrm{y}}$ samples with varying metal composition are shown asprepared (b) and exposed to two different OER potentials, $1.65 \mathrm{~V}$ vs. RHE (c) and $1.90 \mathrm{~V}$ vs. RHE (d). 


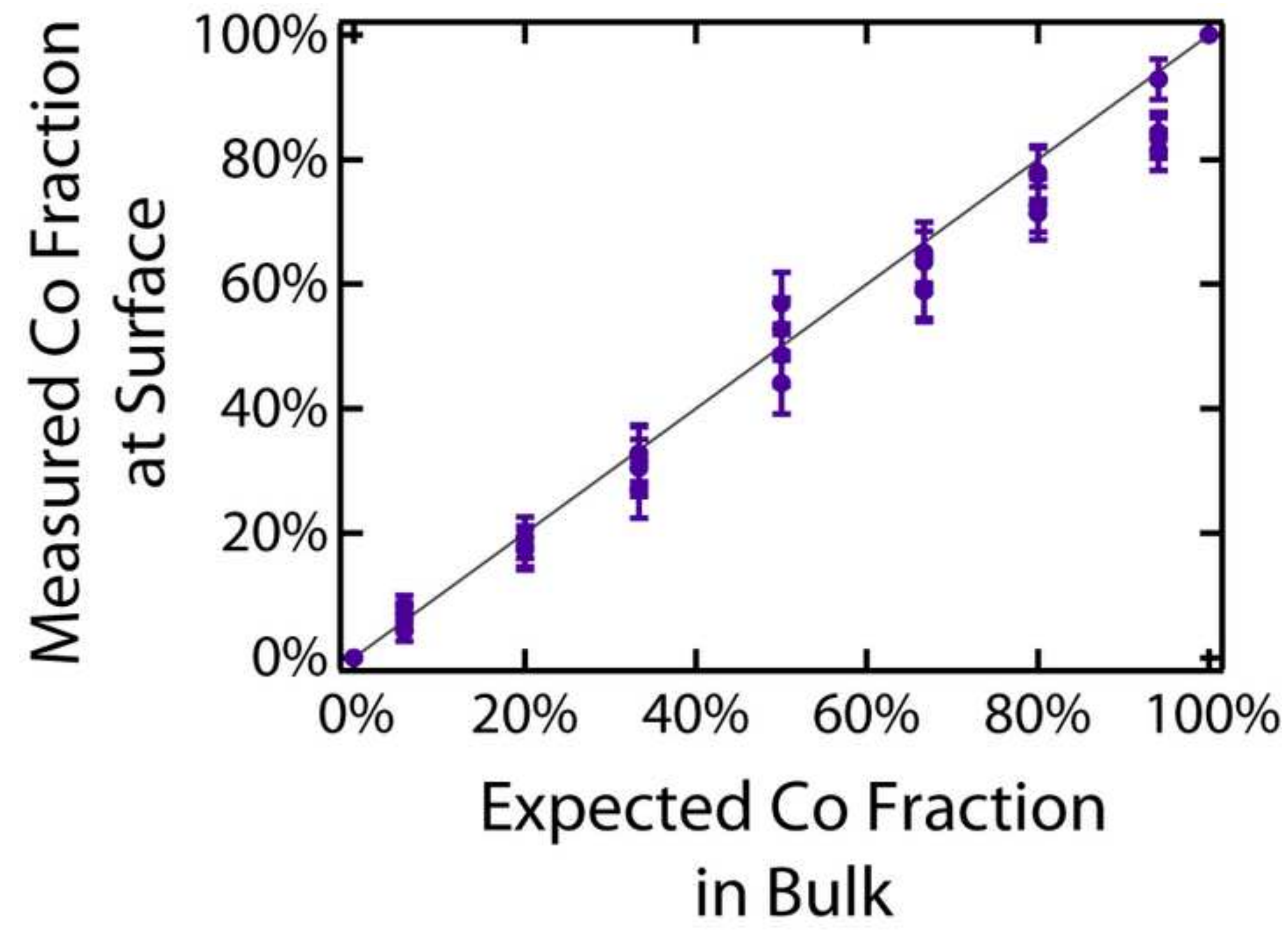




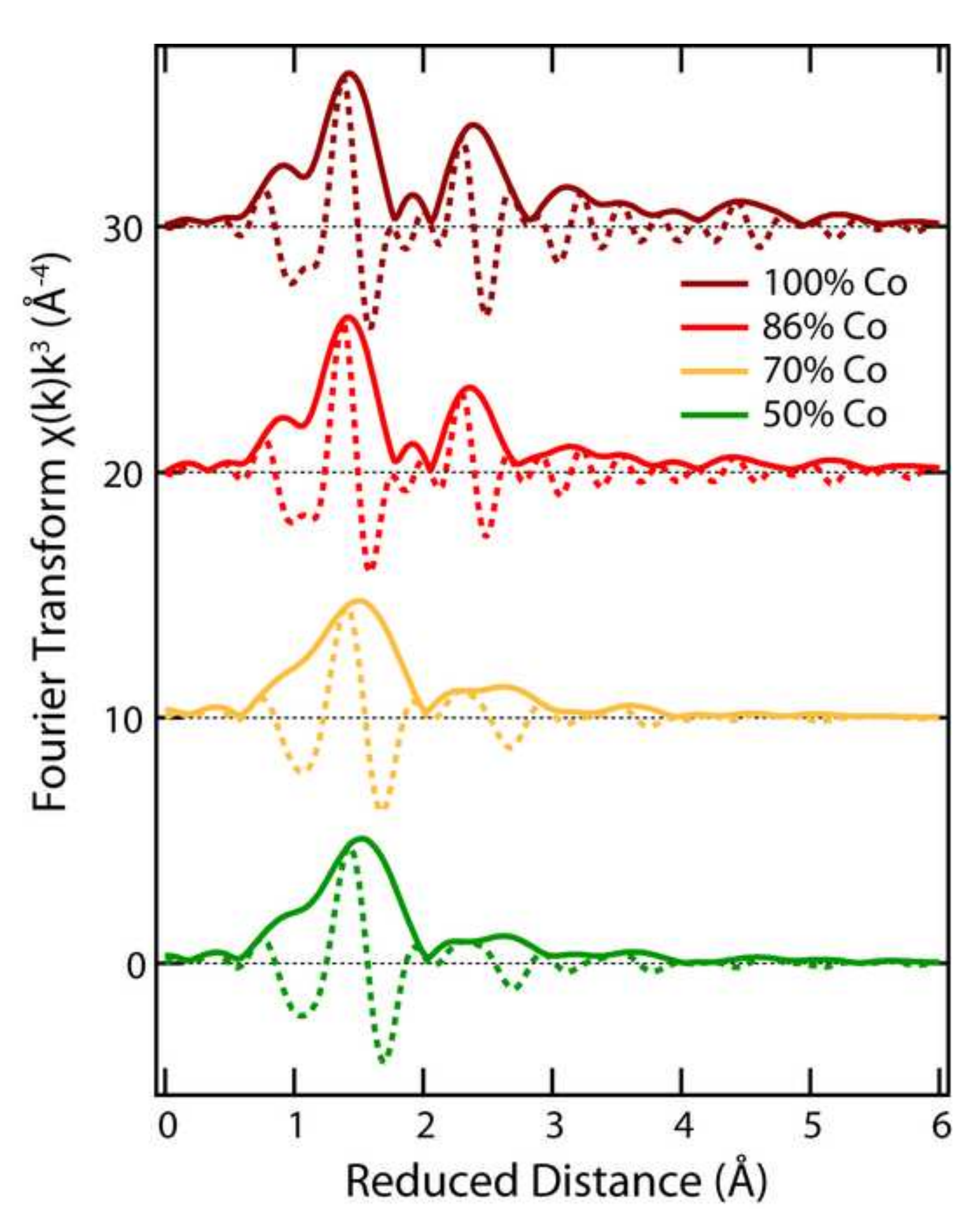

Figure 2
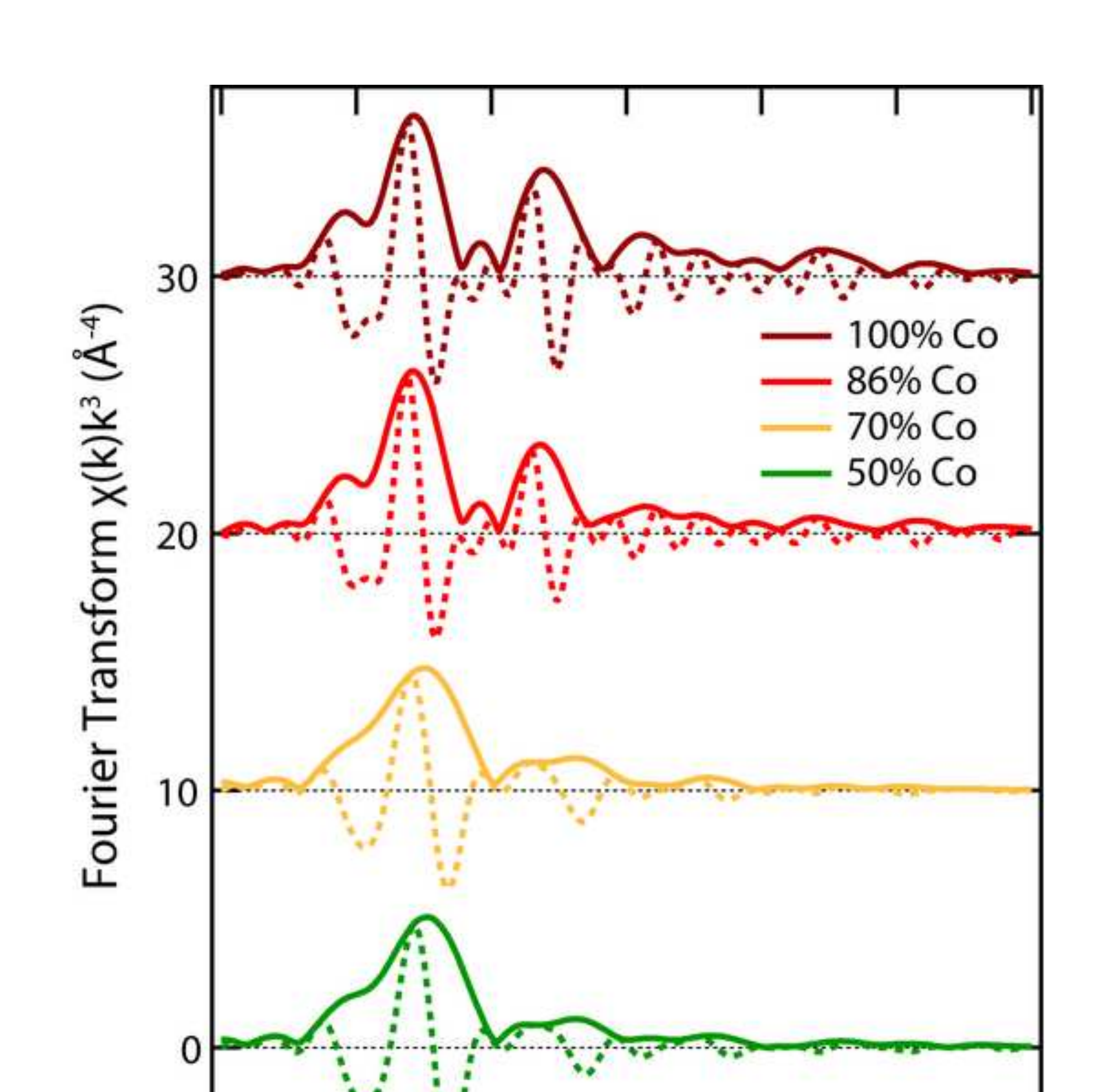

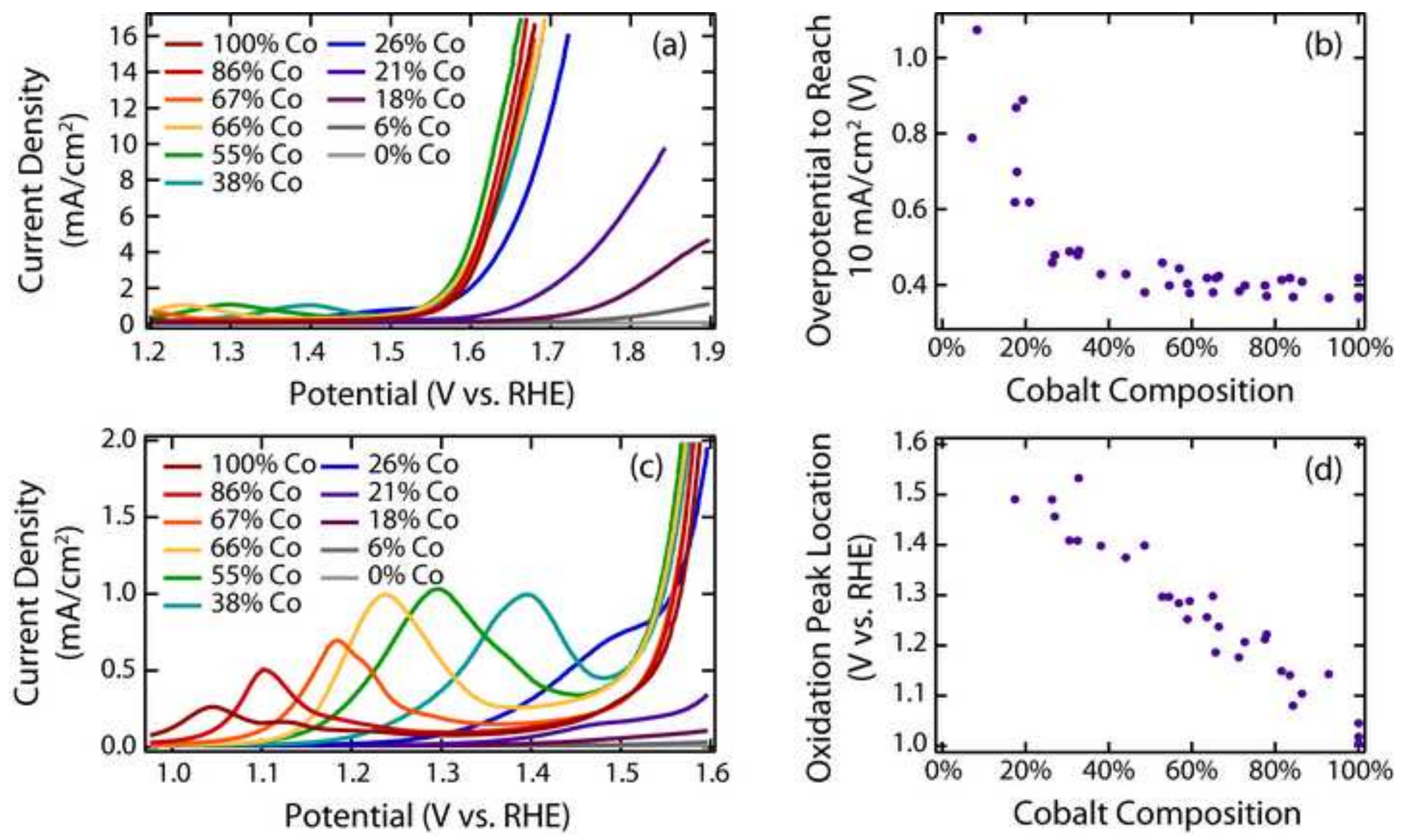


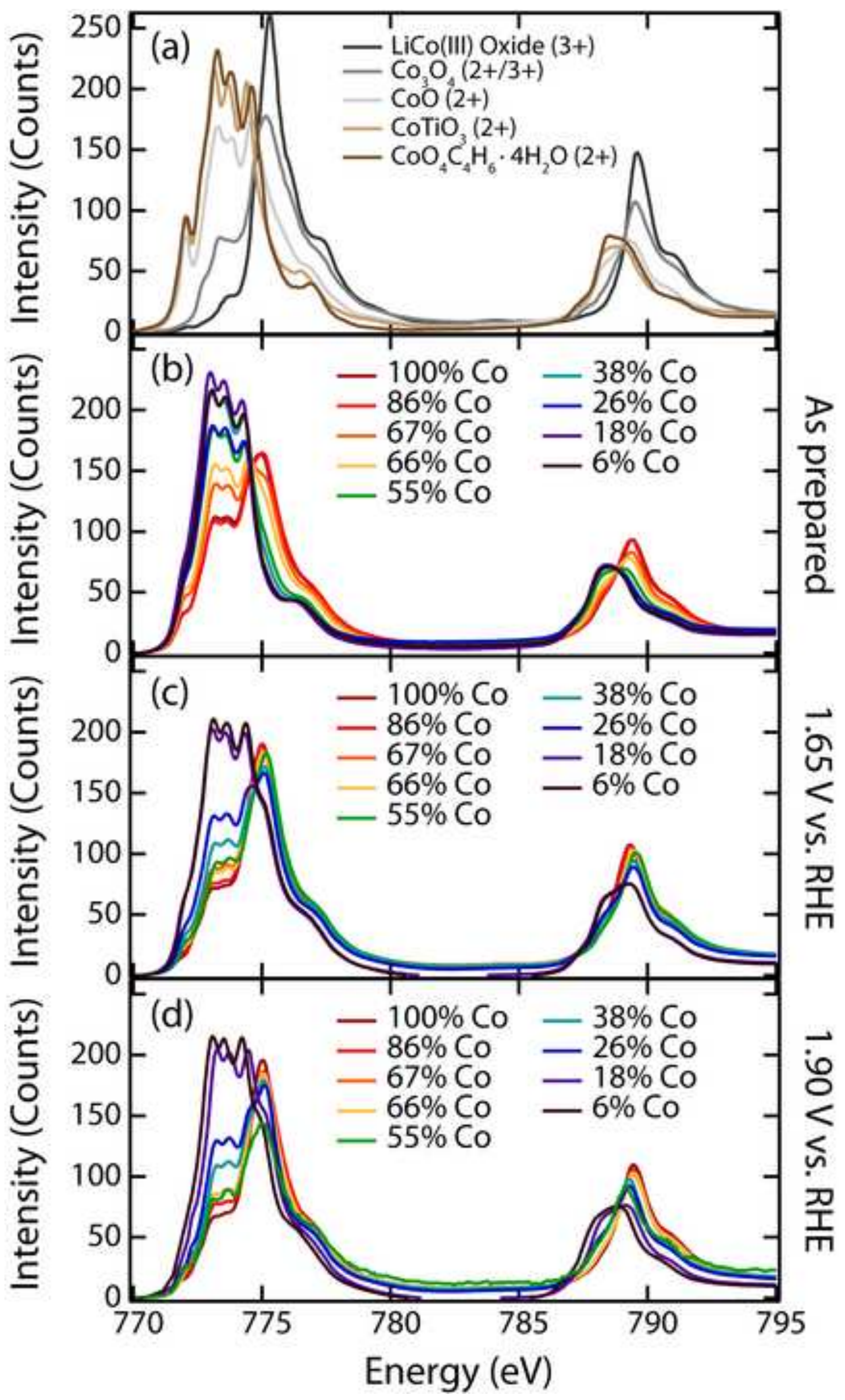

